\title{
Secwépemc People, Land, and Laws. By Marianne Ignace and Ronald E. Ignace. Foreword by Bonnie Leonard. 2017. McGill-Queen's University Press, Montreal and Kingston, Canada. 588 pp.
}

\author{
Eugene N. Anderson ${ }^{1 *}$ \\ ${ }^{1}$ Department of Anthropology, University of California, Riverside, California, USA. \\ *eugene.anderson@ucr.edu
}

Received August 7, 2018

OPEN ठ ACCESS

Accepted August 16, 2018

DOI 10.14237/ebl.9.2.2018.1380

Copyright (c) 2018 by the author(s) licensee Society of Ethnobiology. This is an open-access article distributed under the terms of the Creative Commons Attribution-NonCommercial 4.0 International Public License (https://creativecommons.org/licenses/by-nc/4.0), which permits non-commercial use, distribution, and reproduction in any medium, provided the original author and source are credited.

Secwépemc People, Land, and Laws continues the tradition of monumental ethnographies that characterizes the North American Northwest. Franz Boas, his Native consultants such as George Hunt and William Beynon, and his students and co-workers including John Swanton, James Teit, and Edward Sapir, produced major early works. More recent landmarks include Eugene Hunn and James Selam's (1990) N'chi-Wana, the Big River, Nancy Turner's fivefoot shelf of books, and John Alan Ross' (2011) The Spokan Indians. The Northwest has seen a long succession of ethnographies that are not only comprehensive but are also innovative. Moreover, they are based on particularly tight working relationships between ethnographers and Native American consultants. Sapir not only worked closely with Tom Sayach'apis, but wrote his biography (Sapir 1922); partly in result, Sayach'apis' greatgranddaughter Charlotte Coté is now a respected professor of Native American Studies at the University of Washington (see Coté 1910).

In the present case, the link led to marriage and to Ron Ignace's subsequent $\mathrm{PhD}$. It also led to one of the best ethnographies in the anthropological field. The authors recount the story of the Secwépemc, with help from many elders, and on some chapters from Mike Rousseau, Nancy Turner, and Kenneth Favrholdt.

The Secwépemc were previously known to Canada as the Shuswap. A recent video by Ron Ignace teaches hearers to pronounce the newer name as if spelled according to normal English rules, "sekweh-pemk," but one traditional pronunciation sounds enough like "Shuswap"-leaving off the ending -emc, "people"- to explain the alternative name. Secwépcomes from cwep, "spread out" (as explained on p. 121).

An important feature of the book is the many long accounts and stories provided by elders, in the Secwépemc language, with translations. These greatly increase the value of the work.

The book begins with mythic beginnings, then moves to archaeology (with Mike Rousseau). A great deal of research is now available, showing long, steady development of technologically more complex cultures without dramatic changes. Salish speakers may have moved in from the coast about 5,000 years ago. There is then a very detailed account of the language. Secwépemctsín is one of the Interior Salish languages, members of a language family that dominates southern British Columbia and western Washington. It broke up into component languages over 5,000 years ago, with Interior Salish taking shape by 4,500 years past and Secwépemctsín separating from its neighbors about 2,000 years back.

Their following chapters are on land use and management, transportation, and sense of place. The Secwépemc, like other Northwest Coast peoples, managed the land intensively, taking care of resources. Roots were harvested in such manner that the roots multiplied instead of being depleted. Root and berry management was, in effect, cultivation. Fire was carefully and strategically used to keep root and berry areas clear. Fish were allowed to escape in numbers great enough to assure return. The Fraser River sockeye runs in the early twentieth century were as 
high as 160 million fish (footnote, p. 514); compare that with the dismal situation today. The largest run in recent years was 20 million in 2014 (Lazaruk 2018). The worst was a miserable 853,000 in 2016. Warming of the Fraser River may kill most of the large run coming home in 2018 (Johnson 2018).

Game was not overhunted; the effects of overhunting were well known. As elsewhere, myths, folktales, reminiscences, prayers, songs, and personal stories were used to teach and support the ideology of taking care of the people's life sources.

Further chapters explain kinship, authority, boundaries, lands, and neighbors. The Secwépemc had a well-defined land base, with known boundaries, but within it the various bands or local communities had a more fluid and negotiable tenure. Secwépemc land belonged to the Secwépemc as a whole, and theoretically anyone could fish, hunt, gather, and travel anywhere, though bands had some authority over their key resources.

Chapter 11 discusses the old religion and its survival through reinterpretation and fusion with Christianity. Traditional powers such as healing are slow to fade. Beliefs in transformers, spirit sites and powers, and transformative events attenuate gradually.

Subsequent chapters describe the mounting disasters attendant on white settler invasion. Lands were appropriated till there is almost nothing left. Resources were destroyed. Finally came the horrors of compulsory residential school attendance in the midtwentieth century, with its legacy of language and culture loss and appalling personal abuses. The authors are too merciful to go into details on this latter problem or on its effects. I shall respect their silence; most readers of this review will have some sense of the results of what we now recognize as a genocidal fascist policy.

The Secwépemc had their own ways of commenting. On pages 481-489, the Ignaces recount several stories that gently but pointedly satirize the settler world and cut it down to size. The stories are largely adaptations of old forms of critical narration. The most interesting is a fusion of Secwépemc folklore with a "Jack tale." Jack tales are a widespread genre of folk fiction in which poor but clever Jack wins the king's daughter, usually by managing to perform three tasks that the king sets him, sure that Jack will not accomplish it, but the king's daughter falls in love with the lowly but clever lad and helps him win. These stories are French in origin ("Jack" was originally Jacques), though common in AngloAmerican folklore, and I suppose the Secwépemc learned them from French-Canadians. In the case related here, it is not Jack but the Secwépemc culture hero Tllí7sa who gets the better of the "great chief Red-Cap" (a metaphor of the English). The story is a masterpiece of cultural fusion-Secwépemc setting, French-originated tale.

The last chapters are more hopeful, chronicling the Indian rights movement among the Secwépemc and the new plans for the future. The Ignaces are modestly quiet about their enormous accomplishments in teaching the language to new generations and establishing a Secwépemc museum and garden. Their work in the cause of preserving and propagating Secwépemc culture has been tireless, effective, and heroic. It deserves full recognition. This book is only the latest in a long series of major triumphs in the realm of cultural protection. They have also worked hard, along with thousands of other First Nations people, to get land title recognized and get some return of land to groups callously robbed-whether at gun point or in law offices-by too many of the settlers. Many of their calls for fairness echo those of James Teit a century ago (see Thompson 2007); depressingly, the land tenure situation has not greatly improved since his time.

This ethnography is a full account of Secwépemc life and culture, destined to become a classic in Northwest Coast studies. It is also a long and detailed demonstration of the value of Secwépemc culture and the need to preserve that culture and the land and resource base that sustains it.

\section{References Cited}

Coté, C. 2010. Spirits of Our Whaling Ancestors: Revitalizing Makah and Nuu-chah-nulth Traditions. University of Washington Press, Seattle, WA.

Hunn, E., and J. Selam. 1990. Nch'i-Wana, the Big River. University of Washington Press, Seattle, WA.

Johnson, L. 2018. Fraser River is Now So Warm It May Kill Migrating Sockeye Salmon [web page]. CBC News. Available at: https://www.cbc.ca/news/ canada/british-columbia/sockeye-salmon-watertemperature-1.4771607. Accessed on August 3, 2018.

Lazaruk, S. 2018. Fraser River Sockeye Salmon Fishing Bonanza to Start Next Week [web page]. Vancouver Sun. Available at: https:// 


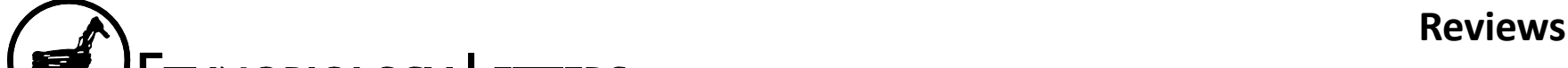

vancouversun.com/news/local-news/fraser-riversockeye-salmon-fishing-bonanza-to-start-next-week. Accessed on August 3, 2018.

Ross, J. A. 2011. The Spokan Indians. Michael J. Ross, Spokane, WA.

Sapir, E. 1922. Sayach'apis, a Nootka Trader. In American Indian Life, edited by E. C. Parsons, pp. 297 -323. B. W. Heubsch, New York.
Thompson, J. 2007. Recording Their Story: James Teit and the Tabltan. Canadian Museum of Civilization, Ottawa, Douglas and McIntyre, Vancouver, and University of Washington Press, Seattle, WA. 